
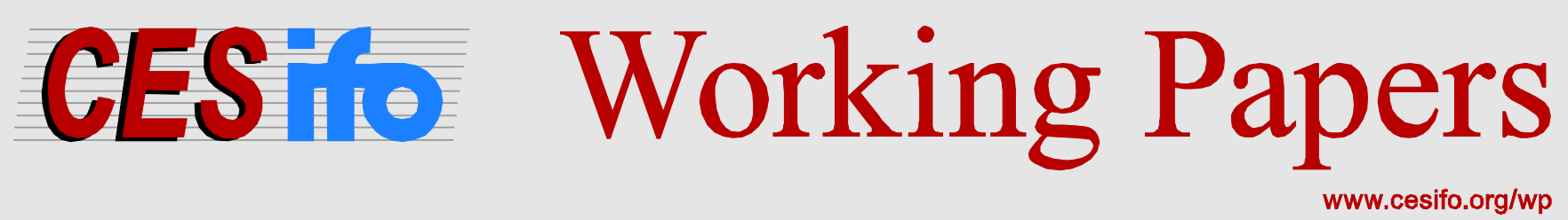

\title{
The Dynamics of Dictator Behavior
}

\author{
Markus Sass \\ Florian Timme \\ Joachim Weimann
}

\section{CESIFO WORKING PAPER NO. 5348 \\ CATEGORY 13: BEHAVIOURAL ECONOMICS \\ MAY 2015}
An electronic version of the paper may be downloaded
- from the SSRN website: Www.SSRN.com
- from the RePEc website: Www.RePEc.org
- from the CESifo website: www.CESifo-group.org/wp




\title{
The Dynamics of Dictator Behavior
}

\begin{abstract}
Choosing between selfish and non-selfish behavior in real life is a repeated decision with varying time spans between repetitions. To learn more about the dynamics of altruistic behavior, we use repeated standard dictator experiments. The dynamics of prosocial behavior in these experiments depends on the strength of several effects that influence gift giving in experiments of this kind. In particular, we investigate how social distance influences behavior in repeated dictator experiments and what kinds of behavioral dynamics are covered by a social norm. Furthermore, we vary the number of repetitions of the dictator game and the length of the time span between the repetitions (from two hours up to two weeks). We identify the moral self-licensing effect as an important determinant of the behavioral dynamics in repeated dictator games and show that this is covered by a social norm.
\end{abstract}

JEL-Code: C910, C730.

Keywords: dictator game, image effect, repeated experiments, dynamics of behavior, moral selflicensing.

Markus Sass

Otto-von-Guericke-University

Faculty of Economics \& Management

Universitätsplatz 2

Germany - 39016 Magdeburg

Markus.Sass@ovgu.de
Florian Timme

Otto-von-Guericke-University

Faculty of Economics \& Management

Universitätsplatz 2

Germany - 39016 Magdeburg

Florian.Timme@ovgu.de

\author{
Joachim Weimann* \\ Otto-von-Guericke-University \\ Faculty of Economics \& Management \\ Universitätsplatz 2 \\ Germany - 39016 Magdeburg \\ joachim.weimann@ww.uni-magdeburg.de
}

*corresponding author 


\section{Introduction}

The study of social (or other-regarding) preferences has been one of the most important topics for experimental economists during the last three decades. The discovery that this kind of preferences plays an important role in many significant economic situations was one of the most impressive findings coming from economics laboratories. ${ }^{1}$ These findings provoked the development of new theories (see, e.g., Fehr and Schmidt (1999), Bolton and Ockenfels (2000)) and changed the way economists think about human decisions. Today most economists know, for example, that human beings, because they do not always behave strictly selfishly, are not helplessly caught in the rationality trap described by the prisoner's dilemma. ${ }^{2}$

On the other hand, there are some concerns that experimental findings will not carry over to this field due to methodical problems. Levitt and List (2007) started a debate about the external validity of laboratory experiments. Besides general comments on the pros and cons of experiments conducted in the laboratory ${ }^{3}$, one strand of the literature started to test the crucial methodological points empirically. For example, Barmettler et al. (2012) investigated the effect of the "experimenter-subject" interaction under laboratory conditions. Slonim and Roth (1998), Cameron (1999) and, more recently, Andersen et al. (2011) investigated whether social preferences disappear under high stakes and Fehr and List (2004) asked if student subjects show significantly higher degrees of social preferences than non-student subjects.

One of the concerns of Levitt and List (2007) is the generalizability of findings from one-shot experiments. They claim that prosocial behavior in one-shot lab experiments might indicate concerns for reputation building rather than prosocial preferences, because "personal experiences may [effectively] cause subjects to play these one-shot games as if they have some repetition." Levitt and List also address the fact that "social dilemmas are typically not one-time encounters, but rather repeated games" and raise the question whether an "effect observed in the lab manifests itself over a longer time period."

These concerns will be the focus of this paper. Indeed, most real life situations in which people have to decide whether to be selfish or to behave altruistically are not single events which come up once in a lifetime. Usually, we have to decide repeatedly to give something to a beggar, to forgo individual advantages in order to help others or just to be nice to others. The time span

\footnotetext{
${ }^{1}$ See Cooper and Kagel (forthcoming) for a selective overview.

${ }^{2}$ Barmettler et al. (2012, p. 18) present a long list of examples of "important dimensions of economic activity" in which the existence of social preferences has a strong impact.

${ }^{3}$ Falk and Heckman (2009), Bardsley et al. (2010), Croson and Gächter (2010), Henrich et al. (2010).
} 
between such situations may vary, but we can be very sure that we will be confronted with the same decision once again sooner or later. In order to understand the rules that altruistic behavior follows, it is therefore of importance to know more about the dynamics of the behavior driven by social preferences. More precisely, the question arises as to whether the repetition of identical situations will have an impact on prosocial behavior.

Surprisingly, the literature is rather quiet about the dynamics aspect. What forces (if any) are at work if decisions concerning one's selfishness are repeated? The stability of prosocial behavior was investigated for the first time by Brosig et al. (2007), who conducted a series of repeated modified dictator experiments. Between the repeated experiments there was a time span of four weeks. They observed that the behavioral dynamics had only one direction: from less selfish behavior to more selfish behavior. Sass and Weimann (2015a) investigated the behavioral dynamics in repeated trust and mutual gift-giving games and also found that the propensity to give something decreases over the repetitions of the games. Sass and Weimann (2015b) report the same for a series of repeated standard public good games.

In this paper, we use the standard dictator game to investigate the dynamics of social behavior in a very direct manner. Dictator games are particularly useful for examining social preferences because the dictator's decision does not depend on any strategic consideration but only on his or her preference over alternative payoff distributions. Furthermore, it is well known that dictator games are very sensitive to the particular experimental design. List (2007) and Bardsley (2008), for example, discovered that dictator behavior changed dramatically when the strategy space is widened. ${ }^{4}$ Oxoby and Spraggon (2008) and Cherry et al. (2002) show that the willingness to give money to the recipient heavily depends on the source of the money. In the case in which the dictators had to work for their endowment, the gifts to the recipient dropped to zero. In this paper, we focus on two aspects of the dictator experiment that seem to have a rather stable influence on the transfer to the recipient: the observability of behavior and the influence of social norms.

There is strong empirical evidence that the observability of gifts made by the dictator is important. Most of the altruistic behavior in experiments and in real life seems to be driven by the wish to demonstrate one's own altruism to others. Ariely et al. (2009) distinguish between three different motivations for altruistic behavior. Intrinsic altruism is the true form of concern for others. Extrinsic motives are driven by personal advantage from behaving altruistically. Image

\footnotetext{
${ }^{4}$ In their experiments, the dictators are not only allowed to give money to the recipient but also to take money away from the recipient.
} 
motivation stems from the wish to demonstrate altruistic behavior in order to maintain a good image. This image effect seems to be the most powerful motivation for many forms of altruistic behavior. Harbaugh (1998a), for example, shows empirically that charitable transfers to universities are predominantly motivated by a prestige motive. ${ }^{5}$ A necessary condition for letting the image or prestige effect work is that the act of being altruistic can be observed by others. This explains why double-blind treatments reveal lower donations in dictator games. Further evidence for the importance of behavior being observable comes from Andreoni and Petrie (2004). They show that the observability of donations is very important for the success of fund raising activities. Rege and Telle (2004) show that implicit social approval is an important driver for contributions in a public good experiment. Contributions increased strongly when publicly announced. In summary, the literature on altruistic behavior comes to the result that the observability of behavior is of enormous importance, because only if others can observe behavior can voluntary donations be used to maintain a positive image.

Despite this empirical evidence, there is a debate over the role of the experimenter-subject interaction. Hoffman et al. (1996) demonstrate that the behavior of dictators depends on the social distance between subjects and between the dictators and the experimenter. In particular, if the experiment is carried out in a double-blind treatment, in which the experimenter cannot observe the decisions of individual dictators, the donations to the recipients are very small. This finding is challenged by Barmettler et al. (2012), who did not find a strong effect if the experimenter is able to observe the transfers compared to a double-blind treatment. Their explanation for this finding is that the double-blind treatment in other experiments causes an experimenter demand effect that forces subjects to become more selfish. In any case, the observability of behavior seems to be a relevant factor in explaining dictator behavior and we therefore include visibility of dictator behavior as one of the treatment variables in our experiment. Why such an effect is at work, although the subject can be sure of not being observed by the experimenter, is not obvious. The underlying research question is whether the positive effect of "being under observation" on altruistic giving washes out over the repetitions of the experiment or is a constant factor.

Krupka and Weber (2013) have shown that the transfers made in dictator game experiments can be interpreted as the willingness to pay for being in accordance with a social norm. The question we want to address is: if social norms are important in static dictator experiments, what

\footnotetext{
${ }^{5}$ The same is reported by Glazer and Konrad (1996). In their paper, it is shown that charitable giving can be explained as the equilibrium in a signaling game in which giving is a credible signal for the true wealth of the donor. See also Harbaugh (1998b) and Benabou and Tirol (2006).
} 
do these norms say about the appropriateness of behavior in repeated situations? Do they demand that the same transfer always has to be made or are decreasing transfers allowed? We will apply the norm elicitation method introduced by Krupka and Weber to learn more about the underlying norms in repeated settings. For the dynamics of altruistic behavior, it is important to know which behavioral dynamics are covered by social norms.

The effect of the visibility of dictator behavior and the influence of social norms are known from static experiments. The question is: what could be a meaningful hypothesis concerning the dynamics of prosocial behavior? A possible explanation for the decreasing willingness to behave prosocially in identically repeated situations is the moral self-licensing effect (see Merritt et al. (2010) for a recent survey). This effect refers to the observation that people allow themselves to behave less unselfishly after having done something in a selfless manner before. Sass and Weimann (2015a) find evidence for this effect in repeated trust games and repeated mutual gift-giving games as well as in a series of repeated standard public good games (2015b). It seems to be plausible that this effect should also be observable in repeatedly conducted dictator games. To get a comprehensive picture of the moral self-licensing dynamics, we control for the number of identical repetitions and the length of the time span between two experiments. Regarding our research questions, we propose the following hypotheses:

1. The observability effect will be at work in all repetitions of the experiment. We expect that in those treatments in which dictators are observed by the experimenter the transfers to the recipient will always be larger than in those treatments that are conducted under double-blind conditions.

2. Moral self-licensing is covered by a social norm that allows those who behaved prosocially to be more selfish "the next time".

3. Due to moral self-licensing the transfers to the recipient will decrease from repetition to repetition and the decay will be stronger, the shorter the time span between two repetitions. We believe that it makes a difference if the memory of the last session is rather fresh because it happened only two hours earlier rather than two weeks earlier. ${ }^{6}$

Our experiments indeed show that overall altruistic giving decreases over time. The decay is strongest in the first two repetitions and it does not depend on the time span between repetitions.

\footnotetext{
${ }^{6}$ This would be in line with the "hot vs. cold phase effect" reported by Gneezy and List (2006) who find that prosocial behavior declines a few hours into a long-lasting gift exchange experiment. They explain their finding by suggesting strong psychological processes initially trigger positive reciprocity in the "hot" phase and a subsequent cooling down of such influences in the cold phase. In the context of our experiments, we believe that such an effect could be at work after 2 hours, but not after 2 weeks, when a new "hot" phase altogether is triggered.
} 
The effect of observability is strong and constant over the course of the repetitions. Interestingly, it turns out that fixed time intervals of one week between the experimental sessions stabilizes behavior in the double-blind treatment. Furthermore, it turns out that moral self-licensing does indeed seem to be covered by an according social norm.

In section two, we describe the experimental design in more detail; section three presents the results, which are than discussed in the concluding section.

\section{Experimental design}

The key feature of our setup is the identical repetition of one-shot dictator games as opposed to experiments in which subjects face the same decision situation repeatedly within a single session. We will refer to these repetitions as waves. In the time passing by between two waves, we cannot observe what subjects do. This loss of control could be problematic, notably if subjects talk to each other about the experiment and learn something about others' behavior, which in turn might change their own behavior in the next wave. We minimized the risks of such undesired influences by implementing an elaborate procedure of picking up each subject at an individual meeting point, escorting the subject to the lab, and having the subject take a seat inside a single soundproof, opaque booth. After the experiment, each subject left the laboratory individually. Thus, at no point in time did a subject learn of any other subject's involvement in the same experiment.

Upon entering the laboratory, each subject was shown a live video transmission of another room of the laboratory in which the recipients of the dictator game were seated. The resolution of the video image was so low that subjects were unable to recognize the identity of the recipients. Any recipient could only take part once in the context of the experiments conducted for this study and did not receive a show-up fee. The dictators were made aware of this through written instructions (see Appendices A, B).

The dictators were given an endowment of EUR 10, split into ten single EUR 1 coins. They were asked to put the money they wished to give to the recipient into an envelope and keep the rest for themselves. After the dictators left the laboratory, the envelopes were randomly distributed amongst the recipients in the other room. 
A single session lasted 20 minutes. All experiments were conducted at the Magdeburg Experimental Laboratory (MaXLab) at the Otto-von-Guericke-University of Magdeburg. Subjects were recruited by ORSEE (Greiner (2004)).

\section{Behavioral dynamics}

Since we are interested in the dynamics of dictator behavior, our treatments varied with respect to the amount of time between the initial experiment and the subsequent wave(s) and the number of waves in which a dictator took part.

In order to separate the effect of the length of the time span between repetitions, we ran treatments in which the initial experiment was repeated only once but with different spans of time between the start and the second wave: 2 hours $(2 \mathrm{H}), 2$ days (2D), and 2 weeks $(2 \mathrm{~W})$. We compared these treatments with treatments in which the game was repeated three times: after 2 hours, 2 days, and 2 weeks. We also ran a treatment with four waves and a constant time interval of one week between repetitions in order to study the effect of a regularly occurring event which forced the dictators to choose between selfish and non-selfish behavior.

\section{Social distance, single-blind vs. double-blind}

To account for the influence of the observability of behavior, we conducted all the experiments described above in a single-blind and a double-blind treatment. The procedure for the singleblind treatments was straightforward. Upon leaving the booth, the dictators were asked by the experimenter to sign a receipt for the amount of money to be taken home. Dictator behavior was thus directly observable. The dictators knew from the instructions that they would have to sign a receipt immediately after the experiment.

In the double-blind treatments, we let all dictators draw a secret fake identity for the course of the experiment before the start of the first wave. The dictators randomly picked a sealed envelope containing a number of identical paper strips on which the name of a city was printed. The number of paper strips in the envelope corresponded to the number of waves in which the dictator was asked to take part. In each wave, the dictators were ordered to put one of the paper strips into the envelope together with the money they wanted to give to the recipient. This procedure enabled us to track individual behavior without knowing the true identity of the dictator. Between the waves, the dictators kept the paper strips in their private property. They were instructed not to reveal their fake identity to any other person. All the envelopes were collected 
one by one by knocking on the door of the booth and having the dictators put them into a cardboard box held by the experimenter. This whole process was filmed by video camera and transmitted live to the dictators on monitor screens in their booths. Thus, they could satisfy themselves that the experimenter did not open the envelopes immediately after collecting them, making it impossible for the experimenter to identify individual behavior. Again, all information about this procedure was given to the dictators via the instructions before they made their decision. Table 1 summarizes all the treatments:

\begin{tabular}{ccccccccccc} 
Name & 2HSB & 2DSB & 2WSB & 2HDB & 2DDB & 2WDB & 4FSB & 4FDB & 4VSB & 4VDB \\
\hline \hline $\begin{array}{c}\text { Number } \\
\text { of waves }\end{array}$ & 2 & 2 & 2 & 2 & 2 & 2 & 4 & 4 & 4 & 4 \\
\hline $\begin{array}{c}\text { Time } \\
\text { span be- } \\
\text { tween } \\
\text { repeti- } \\
\text { tions }\end{array}$ & 2 hours & 2 days & 2 weeks & 2 hours & 2 days & 2 weeks & 1 week & 1 week & $\begin{array}{c}2 \text { days } \\
2 \text { weeks }\end{array}$ & $\begin{array}{c}2 \text { hours } \\
2 \text { weeks }\end{array}$ \\
\hline $\begin{array}{c}\text { Double- } \\
\text { blind }\end{array}$ & no & no & no & yes & yes & yes & no & yes & no & yes \\
\hline N & 39 & 55 & 33 & 38 & 38 & 36 & 25 & 44 & 32 & 37 \\
\hline \hline
\end{tabular}

Table 1: Treatment overview and number of subjects in each treatment

\section{Norm elicitation}

The underlying idea of Krupka and Weber (2013) is to elicit social norms via an incentivized coordination game. The true social norm serves as a focal point in this game. To apply this method in our experiment, 100 subjects were invited. All of them were seated in a lecture hall with more than 500 seats. The group was divided into two subgroups of 50 and each of these groups was confronted with a different norm elicitation task. Each subject received written instructions in which the repeated dictator experiment in a single-blind treatment was described (see Appendix C). The instructions were numbered with an ID which served as a means to run the norm elicitation process anonymously. The subjects picked up the instructions by themselves in such a way that the ID was not observable for the experimenter.

The two groups differed with respect to the number of times the dictator game in their description was repeated (either once or three times). In each case, the time span between repetitions was one week. In both cases, we listed five possible ways a participant in the dictator experiment could behave in the experiment described. Subjects were asked to indicate how they believed the majority of the members of their group would judge the five ways of behavior from 
a social norm perspective. To do so, they could choose from four evaluations: 'desirable', 'somewhat desirable', 'somewhat undesirable' and 'undesirable'. After all the subjects had made their guesses about the assessments of the majority on a sheet of paper handed out together with the instructions, the results were calculated. Then one of the five possible ways of behavior was randomly determined. Those subjects who marked the assessment the majority had chosen received a payoff of EUR 10. All the other subjects received the show up fee of EUR 5 only. Since the true norm serves as a focal point for the coordination game, the majority decision uncovers the social norm actually at work. Table 2 shows the five possible ways of behavior for the two games.

\begin{tabular}{cccccc} 
& $\begin{array}{c}\text { Sequence of } \\
\text { transfers } \\
\text { I }\end{array}$ & $\begin{array}{c}\text { Sequence of } \\
\text { transfers } \\
\text { II }\end{array}$ & $\begin{array}{c}\text { Sequence of } \\
\text { transfers } \\
\text { III }\end{array}$ & $\begin{array}{c}\text { Sequence of } \\
\text { transfers } \\
\text { IV }\end{array}$ & $\begin{array}{c}\text { Sequence of } \\
\text { transfers } \\
\text { V }\end{array}$ \\
\hline \hline Two waves & 5,5 & 5,2 & 2,2 & 3,2 & 0,0 \\
Four waves & $5,5,5,5$ & $5,2,1,0$ & $2,2,2,2$ & $3,3,2,1$ & $0,0,0,0$ \\
\hline \hline
\end{tabular}

Table 2: Ways of behavior presented to subjects in the norm elicitation experiment

\section{Results}

Table 3 and Figures 1a to 1c present the descriptive results for the six treatments with one repetition of the dictator game grouped by the time span between the first and second game. Three observations are worth mentioning. First, for all three time intervals, the second transfer to the recipient is always smaller than the first transfer. The decay is statistically significant at the five-percent level (Wilcoxon signed-rank tests) with the exception of the single-blind treatment with a 2-day interval $(\mathrm{p}=.10)$ ). On average, the gifts to the recipients decrease by 16.9 percent. Second, for all three time intervals, subjects handed more money over to the recipient in the single-blind treatment than in the double-blind treatment. Third, the difference between the single-blind and double-blind treatments is statistically significant at the five-percent level for the 2-hour and the 2-day treatments but not for the 2-week treatment. 


\begin{tabular}{cccccc} 
& & & Change & Average & Diff \\
\hline \hline Single-blind & 3.56 & 2.79 & $-21.6 \%$ & 3.18 & \\
Double-blind & 2.55 & 2.18 & $-14.5 \%$ & 2.37 & 0.81 \\
\hline & Start & $\mathbf{2 ~ D}$ & & & \\
Single-blind & 3.38 & 3.11 & $-8.0 \%$ & 3.25 & 1.45 \\
Double-blind & 2.05 & 1.55 & $-24.4 \%$ & 1.8 & \\
\hline & Start & $\mathbf{2 ~ W}$ & & & \\
Single-blind & 3.09 & 2.39 & $-22.7 \%$ & 2.74 & \\
Double-blind & 2.81 & 2.39 & $-14.9 \%$ & 2.60 & \\
\hline \hline
\end{tabular}

Table 3: Results two repetitions with 2-hour, 2-day and 2-week time spans

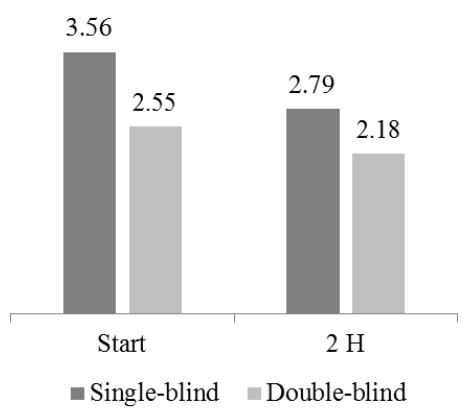

Figure 1a: Average transfers $2 \mathrm{H}$

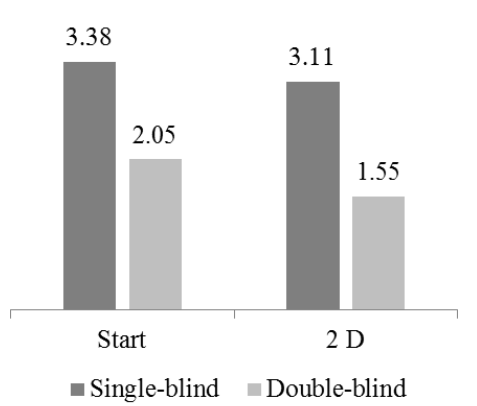

Figure 1b: Average transfers 2D

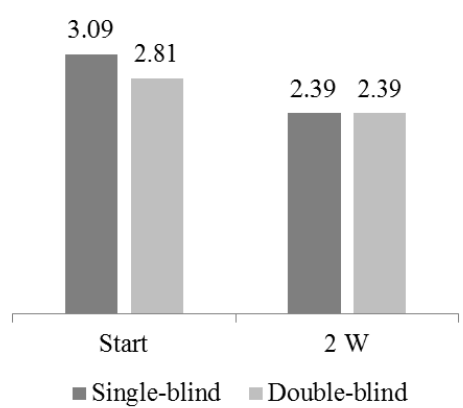

Figure 1c: Average transfers 2W

Table 4 and Figures 2 and 3 display the results for the four treatments with three repetitions grouped by fixed and variable time intervals. Once again we observe that the gifts to the recipients decrease over the course of the experiment.

\begin{tabular}{|c|c|c|c|c|c|c|c|c|c|c|c|}
\hline & Start & Diff & $2 \mathbf{H}$ & Diff & $2 \mathrm{D}$ & Diff & $2 \mathrm{~W}$ & Diff & Change & Average & Diff \\
\hline Single-blind & 3.28 & \multirow{2}{*}{.79} & 2.84 & \multirow{2}{*}{.95} & 2.53 & \multirow{2}{*}{.85} & 2.31 & \multirow{2}{*}{.88} & $-29.6 \%$ & 2.74 & \multirow{2}{*}{.87} \\
\hline \multirow[t]{2}{*}{ Double blind } & 2.49 & & 1.89 & & 1.68 & & 1.43 & & $-42.6 \%$ & 1.87 & \\
\hline & Start & Diff & $1 \mathrm{~W}$ & Diff & $2 W$ & Diff & $3 \mathrm{~W}$ & Diff & Change & Average & Diff \\
\hline Single-blind & 2.80 & \multirow{2}{*}{-.04} & 2.28 & \multirow{2}{*}{.03} & 2.12 & \multirow{2}{*}{.04} & 1.68 & \multirow{2}{*}{-.39} & $-40.0 \%$ & 2.22 & \multirow{2}{*}{-.11} \\
\hline Double-blind & 2.84 & & 2.25 & & 2.16 & & 2.07 & & $-27.1 \%$ & 2.33 & \\
\hline
\end{tabular}

Table 4: Results three repetitions with fixed and varying time intervals 


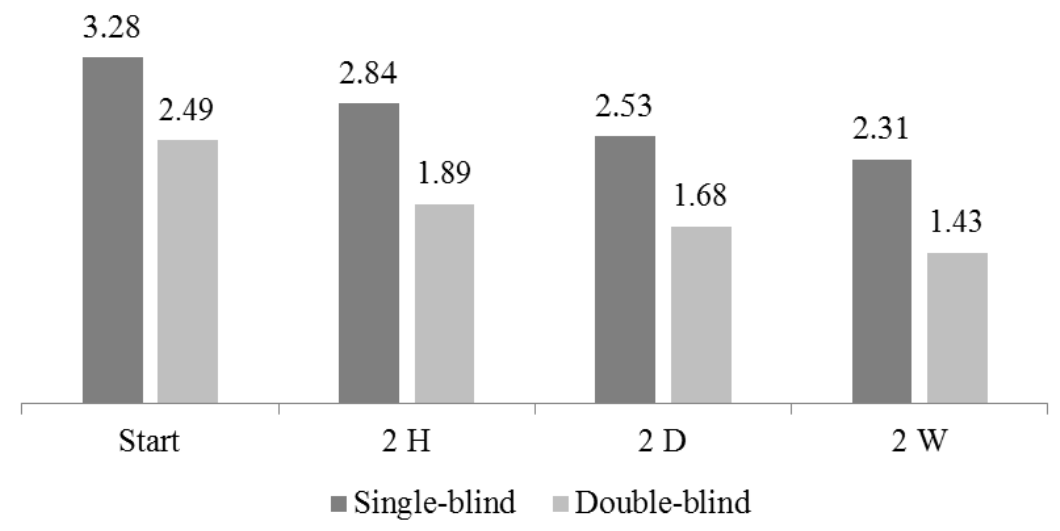

Figure 2: Average transfers three repetitions with varying time intervals

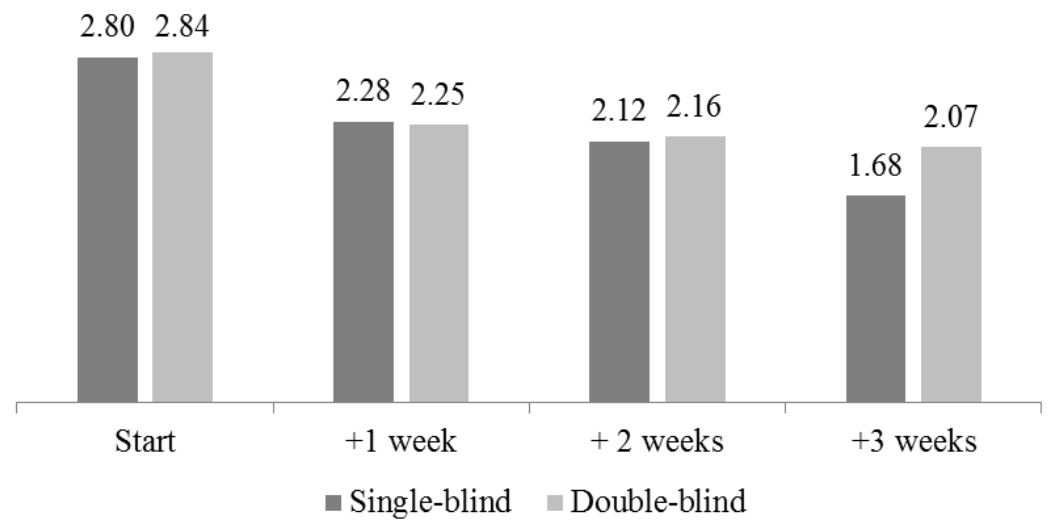

Figure 3: Average transfers three repetitions with fixed time intervals

In the treatment with varying intervals, the single-blind gifts are significantly higher than the double-blind gifts ( $\mathrm{p}<.05$ for the start and $\mathrm{p}<.03$ for 2H, 2D, 2W, Mann-Whitney U-test). The difference between the single-blind and the double-blind treatments measured in euros is nearly the same in all of the four waves the game is played. This implies that the impact of the nonobservability in the double-blind treatments is constant over the course of the experiment, which means that the image motivation for giving money to the recipient does not wash out but works in all repetitions. Furthermore, the transfers to the recipient decrease in both treatments (singleblind and double-blind) from wave to wave. The decay of the transfers is statistically significant at the five-percent level, except for the two middle waves $(2 \mathrm{H}, 2 \mathrm{D})$. From wave 1 to wave 4 , we observe a reduction of 30 percent in the single-blind treatment and 42 percent in the doubleblind treatment. Thus, the moral self-licensing effect seems to be at work under single-blind conditions as well as under double-blind conditions. 
In the treatments with fixed time intervals, we do not find any significant differences between the single-blind and the double-blind treatments. In both treatments, we find a strong and statistically significant reduction of the transfers from the first to the second wave $(\mathrm{p}<.01)$. But after the second wave the behavior is rather stable, particularly in the double-blind treatment. The small decreases in wave three and four are both insignificant $(\mathrm{p}>.3)$. In the single-blind treatment, the difference between the middle waves is also insignificant but the reduction from wave three to wave four is once again significant $(\mathrm{p}<.03)$. The overall decrease in the transfers amounts to 40 percent in the single-blind treatment and 32 percent in the double-blind treatment. The fixation of the time intervals between the repetitions has a stabilizing effect in the double-blind treatment after the first repetition. The overall decrease in the transfers is comparable to the experiments with varying time intervals but the dynamics of the behavior differ. Thus, we find a moral self-licensing effect that peters out after the first repetition in the doubleblind treatment but we do not find an observability effect when the time span between repetitions is fixed. The difference in difference estimation displayed in Table 5 shows that the overall reduction in the transfers does not differ between the treatments with fixed and with varying time intervals.

\begin{tabular}{|c|c|c|c|c|c|c|c|}
\hline & \multicolumn{3}{|c|}{ Wave 1} & \multicolumn{3}{|c|}{ Waves 2-4 } & \multirow[b]{2}{*}{ diff-in-diff } \\
\hline Outcome & var. interv. & fixed interv. & diff & var. interv. & fixed interv. & diff & \\
\hline All Raw & 2.55 & 3.225 & $.675^{* *}$ & 2.267 & 2.903 & $.636^{* * *}$ & -.039 \\
\hline Std. error & .183 & .251 & .310 & .120 & .164 & .203 & .166 \\
\hline
\end{tabular}

Table 5: Difference in difference estimation: fixed and varying time intervals, Means and standard error measured by linear regression.

To obtain a deeper insight in the behavioral dynamics, we transform the gifts into a binary variable (Altruist) indicating whether the dictator behaves in an altruistic manner (Altruist $=1$ ) or not $($ Altruist $=0)$. As a threshold, we use gifts $>2$ for indicating altruism. ${ }^{7}$ This transformation allows us to run a logistic regression with the following model:

$$
\operatorname{logit}(P(\text { Altruist }=1))=\alpha+\beta_{1} D_{1}+\beta_{2} D_{2}+\gamma_{1} W_{1}+\gamma_{3} W_{3}+\gamma_{4} W_{4}
$$

\footnotetext{
${ }^{7}$ We also run our regressions with thresholds of gifts $>1$ and $>3$ and obtain the same results.
} 
$D_{1}$ and $D_{2}$ are treatment variables. Two waves $\left(D_{1}=1\right)$ indicates whether an observation is made in a treatment with two waves or with four waves $\left(D_{1}=0\right)$, Single $\left(D_{2}=1\right)$ stands for a single-blind treatment or a double-blind treatment $\left(D_{2}=0\right)$. $W_{1}$ to $W_{4}$ are categorical variables. $W_{l}$, for example, becomes 1 if the decision made by the dictator is the first in a sequence (Wave $1), W_{3}$ indicates the third and $W_{4}$ the fourth experiment in a sequence. The second decision $\left(W_{2}\right)$ serves as the baseline category. We use clustered error terms to control for multiple observations per subject. Table 6 shows the regression results in terms of log odds.

We do not find any significant impact of the Two waves variable in this model. This indicates that the likelihood of observing altruistic behavior in a particular situation does not depend on whether the dictator is scheduled for two or four waves. However, observability increases the likelihood of finding altruistic behavior as indicated by an odds ratio greater than 1 for the Single variable, which is also significant at the five-percent level. This confirms our conjecture that the observability of behavior has a strong and constant impact on the altruistic behavior in all repetitions of the game.

\begin{tabular}{|c|c|c|c|c|c|c|}
\hline \multirow[b]{4}{*}{ Log pseudolikelihood: } & \multirow[b]{4}{*}{-682.28} & & & & \multirow{2}{*}{$\begin{array}{c}\text { Number of obs: } \\
\text { Wald chi(5): }\end{array}$} & 1030 \\
\hline & & & & & & 71.89 \\
\hline & & & & & Prob > chi2: & .00 \\
\hline & & & & & Pseudo R2: & .04 \\
\hline Altruist & Odds Ratio & Robust Std. Err. & $\mathrm{z}$ & $\mathrm{P}>|\mathrm{z}|$ & {$[95 \%$ Conf } & all] \\
\hline Two waves & .98 & .19 & -.09 & .925 & .67 & 1.44 \\
\hline Single & $1.51 * *$ & .30 & 2.09 & .037 & 1.03 & 2.22 \\
\hline Wave 1 & $1.83 * * *$ & .17 & 6.63 & .000 & 1.53 & 2.19 \\
\hline Wave 3 & $.67 * * *$ & .10 & -2.79 & .005 & .51 & .90 \\
\hline Wave 4 & $.57 * * *$ & .08 & -3.83 & .000 & .43 & .76 \\
\hline _cons & .64 & .11 & -2.43 & .015 & .45 & .92 \\
\hline
\end{tabular}

Table 6: Logistic regression altruistic behavior

The odds ratio of the first wave variable is also greater than 1 and highly significant. This confirms that the identical repetition of the dictator games changes the altruistic behavior of the dictators. The first time subjects are in a situation in which they have to decide to behave either altruistically or selfishly obviously differs from subsequent experiences. Thus, it seems fair to say that the altruism we observe in one-shot dictator experiments is the upper bound of altruism subjects are willing to exercise. A similar interpretation is that the moral self-licensing effect is rather pronounced in our repeated dictator experiment. The odds ratios of waves three and four 
are also significant and smaller than one. Compared to the second wave, the willingness to behave altruistically declines with each further repetition.

We run a second regression in order to investigate whether the length of the time span between the subsequent waves has any impact on the altruism shown by the dictators. Table 7 shows the results of the logistic regression using the time spans as independent categorical variables. Interval_2nd takes the value 0 if the second wave takes place after 2 hours; $1 \hat{=} 2$ days; $2 \hat{=} 1$ week and $3 \bumpeq 2$ weeks; where " 2 hours" is used as the baseline category. It turns out that the odds ratios are all close to one and not significant. Therefore, the time between two repetitions seems not to be of importance. While the gifts depend on the number of repetitions, they do not depend on the time that has gone by since the last dictator decision.

\begin{tabular}{|c|c|c|c|c|c|c|}
\hline & & & & & Number of obs: & 377 \\
\hline & & & & & Wald chi(5): & .79 \\
\hline & & & & & Prob > chi2: & .85 \\
\hline Log pseudolikelihood: & -257.99 & & & & Pseudo R2: & .00 \\
\hline Altruist & Odds Ratio & Robust Std. Err. & $\mathrm{z}$ & $\mathrm{P}>|\mathrm{z}|$ & \multicolumn{2}{|c|}{ [95\% Conf. Intervall] } \\
\hline Interval_2nd = 1 & 1.04 & .28 & .14 & .89 & .62 & 1.75 \\
\hline Interval_2nd = 2 & .81 & .24 & -.70 & .48 & .45 & 1.45 \\
\hline Interval_2nd $=3$ & 1.06 & .31 & .19 & .85 & .59 & 1.88 \\
\hline _cons & .79 & .13 & -1.40 & .16 & .57 & 1.10 \\
\hline
\end{tabular}

Table 7: Logistic regression altruistic behavior and time span between repetitions

Summarizing, our results show that:

1. The transfers to the recipients decline if the experiment is repeated.

2. The attenuation effect of repetitions decreases with the number of repetitions.

3. The time span between repetitions is not important, but the number of repetitions is.

4. The observability of altruistic behavior increases the willingness to give money to the recipient. The image motivation for giving is constant over time.

5. Fixed time intervals of one week between repetitions reduce the observability effect.

The first three observations are in line with the hypothesis that people tend to allow themselves more selfishness after having behaved prosocially (moral self-licensing). The question is whether this kind of behavioral dynamics is covered by a social norm or whether moral selflicensing is accompanied by the costs norm violations normally cause. 


\section{Norm elicitation experiment}

Figures 4 and 5 show the results of the norm elicitation task by displaying the absolute number of votes for each of the four possible evaluations of the five sequences of transfers to the recipient. For both treatments (two and four waves), the extreme cases ("always transfer 50 percent of the endowment" and "transfer nothing") are rated as "desirable" and "undesirable". This is not surprising because in the extreme cases the extreme evaluations are clearly the focal points. More interesting are the evaluations of the three transfer sequences between the extremes. In the group evaluating the sequences in the two waves treatment, a rather strong decrease in the transfers is socially accepted. 70 percent of the subjects rated $(5 ; 2)$ as "somewhat desirable", but 66 percent (62 percent) find that $(2 ; 2)((3 ; 2))$ is "somewhat undesirable". Thus, if someone is rather generous in the first wave, he or she acquires the social license to be less generous "the next time".

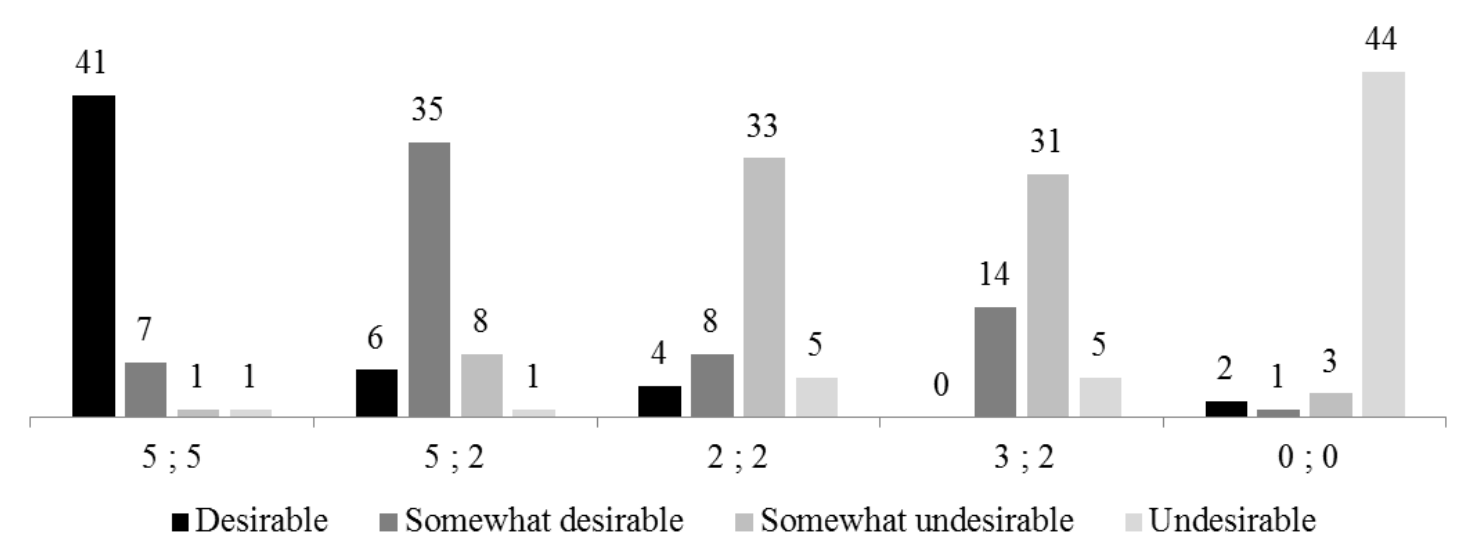

Figure 4: Norm elicitation two waves

In the group rating the sequences of transfer in the treatment with four waves, things are less clear. Giving 5 in the first wave and 2, 1, 0 in the consecutive waves is much less desirable than giving 2 in all four waves, although the sum in both cases is 8 . On the other hand, the sequence $(3 ; 3 ; 2 ; 1)$ receives the highest evaluations of the three middle sequences. One reason may be that the sum of transfers is 9 . But once again it turns out that a decrease in the transfers is socially accepted as long as the transfers in the first waves are perceived as sufficiently generous. 


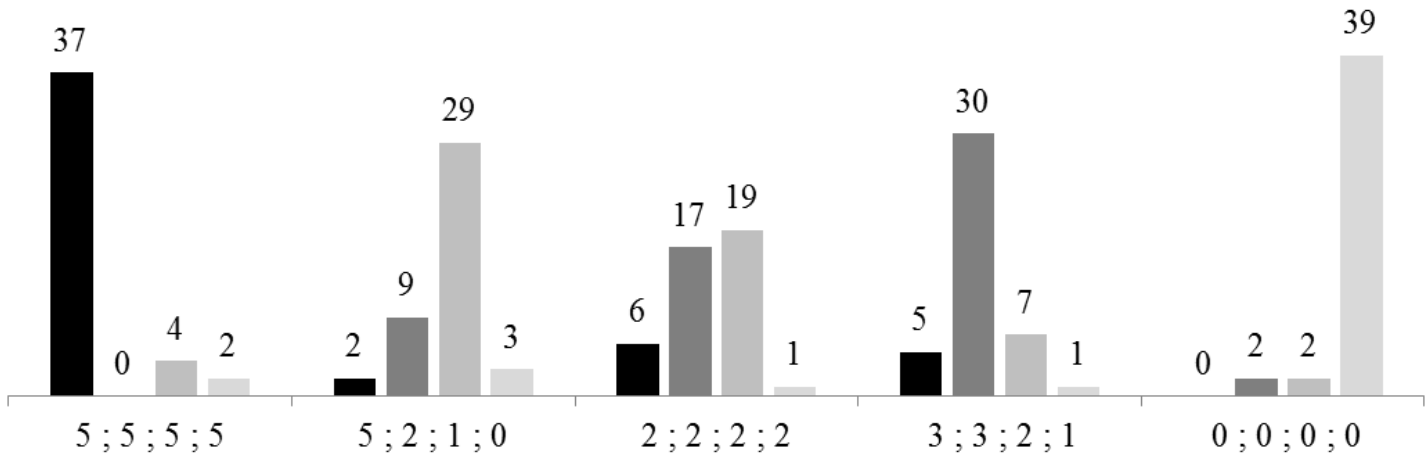

-Desirable $\quad$ Somewhat desirable $\quad$ Somewhat undesirable Undesirable

Figure 5: Norm elicitation four waves

Krupka and Weber (2013) aggregate the evaluations over the four possible steps by assigning numbers to the four evaluations $(1 ; 1 / 3 ;-1 / 3 ;-1)$. Figures 6 and 7 show diagrams in which the mean evaluations are plotted against the sum of transfers over all four waves:

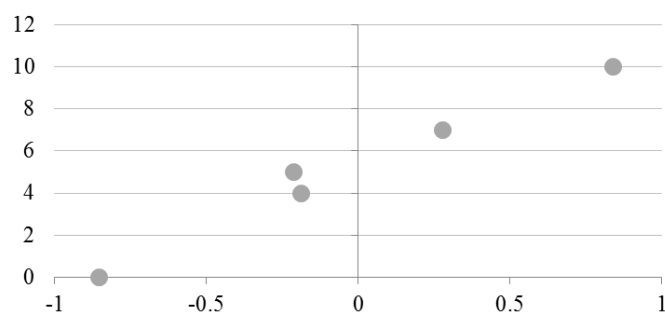

Figure 6: Sum of transfers and evaluations two waves

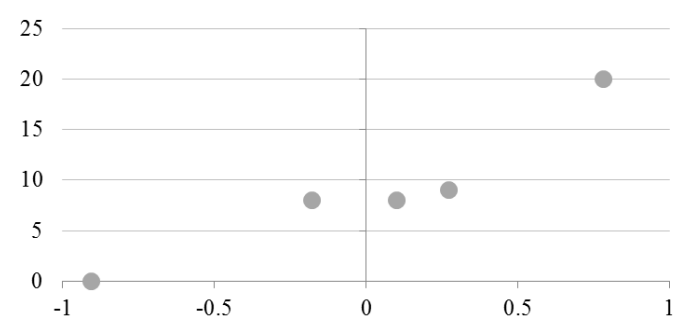

Figure 7: Sum of transfers and evaluations four waves

The correlation between the sum of transfers and the evaluations is highly significant with a correlation coefficient $>.95$. This underlines the finding that the distribution of the transfers over the rounds is not that important as long as the overall transfers are high enough. Therefore, feeling licensed to behave more selfishly after being generous seems to be covered by social approval.

\section{Discussion}

We study the dynamics of social preferences and our experiments demonstrate that altruistic behavior in standard dictator experiments is not constant over time if the experiments are rep- 
licated identically. One possible explanation for the behavioral dynamics found in our experiments is the idea of moral self-licensing: by making an altruistic gift to the recipient, subjects acquire the license to be more selfish the next time. Sachdeva et al. (2009) describe altruistic behavior as a "result from an internal balancing of moral self-worth and the cost inherent in altruistic behavior" (p. 523). In this view, altruistic giving in a dictator game is a tool to create a positive moral identity. Given this moral identity, people feel licensed to behave more selfservingly "the next time". This is in line with our finding that the gifts to the recipients decreased and that the time span between the repetitions does not play a role. For the self-licensing effect it is not of importance when the last altruistic giving had happened, only that it had happened.

Our results also show that the motivation for altruistic giving seem to be multi-dimensional. The fact that the gifts decrease hints at the function they have for moral self-worth. This is in line with the finding of Krupka and Weber (2013) that altruistic giving can be interpreted as an expression of the willingness to pay for following a social norm. On the other hand, the norm elicitation task reveals that decreasing the transfer after being generous is socially accepted.

The fact that the observability of "giving" increases the transfers documents that the image effect described by Ariely et al. (2009) and others also is at work. Finally, even after repetitions and under non-observability, positive amounts of money are handed over. This implies that some measure of "pure altruism" also exists.

The stabilization effect of a fixed time interval of one week in the double-blind treatment cannot easily be explained by any of the motivations we have identified so far. Obviously, the regularity with which subjects were put in the same decision situation seems to have a stabilizing effect. It may be that the regularity helps subjects to find some kind of routine to cope with the decision task. Although this may be plausible, it is pure speculation. It would be interesting to investigate this stabilizing effect in more detail by varying the time span between the regular repetitions.

All in all, it turns out that repeating experiments that uncover social preferences allows us to obtain interesting and important new insights about the character of social preferences and the behavior which is driven by this special kind of preferences. 


\section{References}

Andersen, Steffen, Seda Ertac, Uri Gneezy, Moshe Hoffman and John List (2011): "Stakes Matter in Ultimatum Games", American Economic Review 101 (7), 3427-39.

Andreoni, James and Ragan Petrie (2004): "Beauty, gender and stereotypes: Evidence from laboratory experiments", Journal of Economic Psychology 29 (1), 73-93.

Ariely, Dan, Anat Bracha, and Stephan Meier. 2009. "Doing Good or Doing Well? Image Motivation and Monetary Incentives in Behaving Prosocially", American Economic Review 99 (1), 544-55.

Bardsley, Nicholas (2008): "Dictator game giving: altruism or artefact?", Experimental Economics $11(2), 122-133$.

Bardsley, Nicholas, Robin Cubitt, Graham Loomes, Peter Moffatt, Chris Starmer and Robert Sugden (2010): "Experimental Economics: Rethinking the Rules", Princeton University Press.

Barmettler, Franziska, Ernst Fehr and Christian Zehner (2012): "Big experimenter is watching you! Anonymity and prosocial behavior in the laboratory", Games and Economic Behavior 75 (1), 17-34.

Benabou, Roland and Jean Tirole (2006): "Incentives and prosocial behavior", The American Economic Review 96 (5), 1652-1678.

Bolton, Gary and Axel Ockenfels (2000): "ERC: A Theory of Equity, Reciprocity, and Competition", The American Economic Review 90 (1), 166-193.

Brosig, Jeannette, Thomas Riechmann and Joachim Weimann (2007): "Selfish in the end? : an investigation of consistency and stability of individual behavior", MPRA Paper No. 2035, March.

Cameron, Lisa (1999): "Raising the stakes in the ultimatum game: Experimental evidence from Indonesia", Economic Inquiry 37 (1), 47-59.

Cherry Todd, Peter Frykblom, Jason Shogren (2002): "Hardnose the Dictator", The American Economic Review 92 (4), 1218-1221.

Cooper, David and John Kagel (forthcoming): "Other Regarding Preferences: A Survey of Experimental Results." in: J. Kagel and A. Roth (Eds.), The Handbook of Experimental Economics, Vol. 2, Princeton: Princeton University Press. 
Croson, Rachel and Simon Gaechter (2010): "The science of experimental economics", Journal of Economic Behavior \& Organization 73 (1), 122-131.

Falk, Armin and James Heckman (2009): "Lab experiments are a major source of knowledge in the social sciences", Science 23 (326), 535-538.

Fehr, Ernst and John List (2004): "The hidden costs and returns of incentives - Trust and trustworthiness among CEOs", Journal of the European Economic Association 2 (5), 743 771.

Fehr, Ernst and Klaus M. Schmidt (1999): "A Theory of Fairness, Competition, and Cooperation", The Quarterly Journal of Economics (1999) 114 (3), 817-868.

Glazer, Amihai and Kai Konrad (1996): "A Signaling Explanation for Charity", The American Economic Review 86 (4), 1019-28.

Gneezy, Uri and John List (2006): "Putting Behavioral Economics to Work: Testing for Gift Exchange in Labor Markets Using Field Experiments”, Econometrica 74 (5), 1365-1384.

Greiner, Ben (2004): "An Online Recruitment System for Economic Experiments" In: Kurt Kremer, Volker Macho (Eds.): Forschung und wissenschaftliches Rechnen. GWDG Bericht 63. Ges. für Wiss. Datenverarbeitung, Göttingen, 79-93.

Harbaugh, William (1998a): "The prestige motive for making charitable transfers", The American Economic Review Papers and Proceedings 88 (2), 277-82.

Harbaugh, William (1998b): "What do donations buy?" Journal of Public Economics 67 (2), 269-84.

Henrich, Joseph, Steven Heine and Ara Norenzayan (2010): "The weirdest people in the world". Behavioral and Brain Science 33 (2-3), 61-83.

Hoffman, Elizabeth, Kevin McCabe and Vernon Smith (1996): "Social distance and other-regarding behavior in dictator games", The American Economic Review 86 (3), 653-660.

Krupka, Erin and Roberto Weber (2013): "Identifying Social Norms using Coordination Games: Why does Dictator Game Sharing Vary?", Journal of the European Economic Association $11(3), 495-524$.

Levitt, Steven and John List (2007): "What do laboratory experiments measuring social preferences reveal about the real world?", Journal of Economic Perspectives 21 (2), 153-174. 
List, John (2007): "On the Interpretation of Giving in Dictator Games", Journal of Political Economy 115 (3), 482-193.

Merritt, Anna, Daniel Effron and Benoît Monin (2010): "Moral Self-Licensing: When Being Good Frees Us to Be Bad", Social and Personality Psychology Compass 4 (5), 344-357.

Rege, Mari and Kytel Telle (2004): "The impact of social approval and framing on cooperation in public good situations", Journal of Public Economics 88 (7-8), 1625-1644.

Oxoby, Robert and John Spraggon (2008): "Mine and yours: Property rights in dictator games", Journal of Economic Behavior \& Organization 65 (3-4), 703-713.

Sachdeva, Sonya, Rumen Iliev and Douglas Medin (2009): "Sinning Saints and Saintly Sinners. The Paradox of Moral Self-Regulation", Psychological Science 20 (4), 523-528.

Sass, Markus and Joachim Weimann (2015a): "Moral Self-Licensing and the Direct Touch Effect", CESifo Working Paper No. 5174.

Sass, Markus and Joachim Weimann (2015b): "The Peculiar Power of Pairs", Working paper in preparation.

Slonim, Robert and Alvin Roth (1998): "Learning in high stakes ultimatum games: An experiment in the Slovak Republic", Econometrica 66 (3), 569-596. 


\section{Appendix A: Instructions single-blind treatments}

The following instructions are the English translation of the original German instructions.

The original instructions are available from the corresponding author.

These instructions were given to all subjects taking part in any of the single-blind treatments.

- You will now take part in an experiment within the context of experimental economics. In this experiment, you can earn money that will be paid out to you in cash at the end of the experiment.

- You and another subject are part of the following decision situation. The other subject's identity will not be revealed to you at any point in time. Likewise, your identity will not revealed to the other subject. Thus, the interaction is completely anonymous.

- You have been endowed with EUR 10, split up into 10 EUR 1 coins. You are asked to divide this amount of money between yourself and the other subject. Please decide on the amount of money (if any) that you want to give to the other subject by placing the equivalent number of coins into the envelope in front of you (please do not seal the envelope just yet, thank you!)

Additional information on the other subject:

- At this moment the other subject is sitting in the adjacent room. Upon entering the laboratory, you were shown a live video transmission from that room showing the other participants in this experiment. To ensure anonymity, we deliberately chose a low resolution.

- The other subject was - just like you - invited randomly from the general MaXLab subject pool.

- The other subject will take part in this experiment today for the first and only time.

- The other subject will only receive the money that you give to him or her. There is no show-up fee or any other monetary compensation.

- The other subject does not make a decision in the context of this experiment. 
- Procedure of this experiment

○ Please wait inside your booth until you are picked up by an experimenter

- Please hand over the envelope to the experimenter and sign a receipt for the amount of money you want to take home.

- You will then leave the laboratory on your own without encountering any other participant of this experiment.

- The experimenter will take your envelope and the envelopes of other subjects that had the same role as yourself and randomly distribute them among the participants in the adjacent room. 


\section{Appendix B: Instructions double-blind treatments}

The following instructions are the English translation of the original German instructions.

The original instructions are available from the corresponding author.

The instructions in the double-blind treatments slightly differed with respect to the number of repetitions and the time intervals between two repetitions. Differences in the instructions are highlighted in bold print.

- You will now take part in an experiment within the context of experimental economics. In this experiment, you can earn money that will be paid out to you in cash at the end of the experiment.

- The experiment consists of two parts (2HDB, 2DDB, 2WDB) / consists of four parts (4VDB) / has duration of four weeks (4FDB). The peculiarities that result from this experimental setup are explained in detail in the following instructions. Please read them carefully. Thank you!

- You and another subject are part of the following decision situation. The other subject's identity will not be revealed to you at any point in time. Likewise, your identity will not revealed to the other subject. Thus, the interaction is completely anonymous.

- You have been endowed with EUR 10, split up into 10 EUR 1 coins. You are asked to divide this amount of money between yourself and the other subject. Please decide on the amount of money (if any) that you want to give to the other subject by placing the equivalent number of coins into the envelope in front of you. The experimenter will then take your envelope and the envelopes of other subjects that had the same role as you and randomly distribute them among the participants in the adjacent room.

- Upon entering the laboratory, you were asked to randomly choose an envelope containing strips of paper on which the name of a city are printed. The name of the city is your identity in the context of this experiment. Please treat this identity confidentially. Nobody but you should know the name of the city you drew. Please add ONE of the strips to the envelope with the money that you want to give to the other subject. Please keep the other strips and bring them with you for the second experiment (2HDB, 2DDB, 
2WDB) / the other experiments (4VDB, 4FDB). The city identity allows us to monitor your individual behavior without knowing your true identity. Thus, the decisions you make in this experiment are completely anonymous and not even the experimenter will know what you have decided. To ensure anonymity, we have set up a live video transmission that you can see on the screen in front of you. It allows you to monitor the process of us collecting all envelopes, so you can be sure that we do not open your envelope immediately after collection.

- Additional information on the other subject:

- At this moment the other subject is sitting in the adjacent room. Upon entering the laboratory, you were shown a live video transmission from that room showing other participants in this experiment. To ensure anonymity, we deliberately chose a low resolution.

- The other subject was - just like you - invited randomly from the general MaXLab subject pool.

- The other subject will take part in this experiment today for the first and only time.

- The other subject will only receive the money that you give to him or her. There is no show-up fee or any other monetary compensation.

- The other subject does not make a decision in the context of this experiment. 


\section{Appendix C: Instructions norm elicitation experiment}

The following instructions are the English translation of the original German instructions. The original instructions are available from the corresponding author.

While PAGE 1 and PAGE 2 of the instructions below are identical for both norm elicitation experiments that we conducted (two waves / four waves), PAGE 3 (the data sheet) differs. Therefore both versions of the data sheets are included in this appendix.

\section{PAGE 1: INSTRUCTIONS}

Please read these instructions carefully. If you have any questions, please raise your hand and wait for an experimenter to come to your seat.

You will receive a show-up fee of EUR 5 for participating in this experiment. You might receive an additional monetary compensation depending on the decisions that you and other participants make in the context of this experiment.

Note: Please do not communicate with other subjects during this experiment verbally or in any other way. Subjects not obeying this rule will be excluded from the experiment and will not receive a payment. Thank you!

50 subjects will be taking part in this experiment. All of them are sitting in this lecture hall at the same time. Your task is to indicate what you estimate or believe the majority of the other subjects think is a "socially appropriate" or "socially desirable" behavior in a certain decision situation. If your estimation is identical with the estimation of the majority of other subjects, you will receive an additional EUR 5 on top of the show-up fee, thus EUR 10 in total. If not, you will only receive the show-up fee that every participant will be paid in any case.

The situation in question is given by an experiment that other subjects took part in or will take part in at a different point in time in Magdeburg. You'll find the description of this experiment on the next page. Questions you might have will be answered at your seat. Please raise your hand if you have any.

On the third page you will find the actual questions you are asked to answer. To answer the questions, just mark one of the given response options. This is not about what you personally think is the appropriate behavior but what the majority of the other subjects think.

Procedure of this experiment: 
1. Please read the description of the base game on page 2 carefully.

2. Answer the question on page 3 (data sheet)

3. Separate page 3 from these instructions, fold it once and hand it to an experimenter when asked to do so.

4. The data sheets will be evaluated immediately after collection.

5. You will find an ID on each page in the top right corner. After the evaluation of the data sheets, we will list all IDs that qualify for a payment of EUR 10 and all IDs that qualify for a payment of EUR 5. Please line up at the payment desk corresponding to your ID when asked to do so.

\section{PAGE 2: DESCRIPTION OF THE BASE GAME}

The following box includes instructions of an experiment that other subjects took part in or will take part in at a different point in time in Magdeburg.

Please read these instructions carefully. Although you will not take part in the experiment described in these instructions, it is important that you are familiar with them.

- You will now take part in an experiment within the context of experimental economics. In this experiment, you can earn money that will be paid out to you in cash at the end of the experiment.

- You and another subject are part of the following decision situation. The other subject's identity will not be revealed to you at any point in time. Likewise, your identity will not revealed to the other subject. Thus, the interaction is completely anonymous.

- You have been endowed with EUR 10, split up into 10 EUR 1 coins. You are asked to divide this amount of money between yourself and the other subject. Please decide on the amount of money (if any) that you want to give to the other subject by placing the equivalent number of coins into the envelope in front of you (please do not seal the envelope just yet, thank you!) 
Additional information on the other subject:

- At this moment the other subject is sitting in the adjacent room. Upon entering the laboratory, you were shown a live video transmission from that room showing other participants in this experiment. To ensure anonymity, we deliberately chose a low resolution.

- The other subject was - just like you - invited randomly from the general MaXLab subject pool.

- The other subject will take part in this experiment today for the first and only time.

- The other subject will only receive the money that you give to him or her. There is no show-up fee or any other monetary compensation.

- The other subject does not make a decision in the context of this experiment.

\section{PAGE 3: DATA SHEET (Two waves)}

The experiment described on page 2 is conducted in a laboratory. Two hours after the experiment, the players that were asked to divide the EUR 10 take part in an identical repetition of the experiment, though they are matched with freshly recruited new partners who only take part in the experiment once.

The following table consists of 5 different possibilities on how a player could behave in the two experiments. You are asked to indicate for each possibility, what you believe the majority of your co-participants think of the "appropriateness" or "social desirability" of the different behaviors. Options range between "very desirable/very appropriate" to "somewhat desirable/somewhat appropriate" to "somewhat undesirable/inappropriate" to "very undesirable/very inappropriate".

Note: Only one of the 5 possibilities is chosen for evaluation. You will receive the additional EUR 5 if you match the choice made by the majority of participants in the randomly drawn row. 


\begin{tabular}{|c|c|c|c|c|}
\hline $\begin{array}{l}\text { Behavior of the subject } \\
\text { dividing the money }\end{array}$ & $\begin{array}{l}\text { very desirable/ } \\
\text { very appropriate }\end{array}$ & $\begin{array}{l}\text { somewhat } \\
\text { desirable/ } \\
\text { somewhat } \\
\text { appropriate }\end{array}$ & $\begin{array}{c}\text { somewhat } \\
\text { undesirable/ } \\
\text { somewhat } \\
\text { inappropriate }\end{array}$ & $\begin{array}{l}\text { very undesirable/ } \\
\text { very inappropriate }\end{array}$ \\
\hline $\begin{array}{l}\text { Amount given 1st experiment: } 5 \text { EUR } \\
\text { Amount given } 2 \text { nd experiment: } 5 \text { EUR }\end{array}$ & & & & \\
\hline $\begin{array}{l}\text { Amount given 1st experiment: } 5 \text { EUR } \\
\text { Amount given 2nd experiment: } 2 \text { EUR }\end{array}$ & & & & \\
\hline $\begin{array}{l}\text { Amount given 1st experiment: } 2 \text { EUR } \\
\text { Amount given 2nd experiment: } 2 \text { EUR }\end{array}$ & & & & \\
\hline $\begin{array}{l}\text { Amount given 1st experiment: } 3 \text { EUR } \\
\text { Amount given 2nd experiment: } 2 \text { EUR }\end{array}$ & & & & \\
\hline $\begin{array}{l}\text { Amount given 1st experiment: } 0 \text { EUR } \\
\text { Amount given 2nd experiment: } 0 \text { EUR }\end{array}$ & & & & \\
\hline
\end{tabular}

\section{Please make ONE mark in each ROW!}

\section{PAGE 3: DATA SHEET (Four waves)}

The experiment described on page 2 is conducted in a laboratory. One week after the experiment, the players that were asked to divide the EUR 10 take part in an identical repetition of the experiment, though they are matched with freshly recruited new partners who only take part in the experiment once. In the same way the game is repeated twice more, such that the game is played a total of four times at intervals of one week each and with new partners in each week. The following table consists of 5 different possibilities on how a player could behave in the four experiments. You are asked to indicate for each possibility, what you believe the majority of your co-participants think of the "appropriateness" or "social desirability" of the different behaviors. Options range between "very desirable/very appropriate" to "somewhat desirable/somewhat appropriate" to "somewhat undesirable/inappropriate" to "very undesirable/very inappropriate".

Note: Only one of the 5 possibilities is chosen for evaluation. You will receive the additional EUR 5 if you match the choice made by the majority of participants in the randomly drawn row. 


\begin{tabular}{|c|c|c|c|c|}
\hline $\begin{array}{l}\text { Behavior of the subject } \\
\text { dividing the money }\end{array}$ & $\begin{array}{l}\text { very desirable/ } \\
\text { very appropriate }\end{array}$ & $\begin{array}{l}\text { somewhat } \\
\text { desirable/ } \\
\text { somewhat } \\
\text { appropriate }\end{array}$ & $\begin{array}{c}\text { somewhat } \\
\text { undesirable/ } \\
\text { somewhat } \\
\text { inappropriate }\end{array}$ & $\begin{array}{l}\text { very undesirable/ } \\
\text { very inappropriate }\end{array}$ \\
\hline $\begin{array}{l}\text { Amount given 1st experiment: } 5 \text { EUR } \\
\text { Amount given } 2 \text { nd experiment: } 5 \text { EUR } \\
\text { Amount given 3rd experiment: } 5 \text { EUR } \\
\text { Amount given 4th experiment: } 5 \text { EUR }\end{array}$ & & & & \\
\hline $\begin{array}{l}\text { Amount given 1st experiment: } 5 \text { EUR } \\
\text { Amount given 2nd experiment: } 2 \text { EUR } \\
\text { Amount given 3rd experiment: } 1 \text { EUR } \\
\text { Amount given 4th experiment: } 0 \text { EUR }\end{array}$ & & & & \\
\hline $\begin{array}{l}\text { Amount given 1st experiment: } 2 \text { EUR } \\
\text { Amount given 2nd experiment: } 2 \text { EUR } \\
\text { Amount given 3rd experiment: } 2 \text { EUR } \\
\text { Amount given 4th experiment: } 2 \text { EUR }\end{array}$ & & & & \\
\hline $\begin{array}{l}\text { Amount given 1st experiment: } 3 \text { EUR } \\
\text { Amount given 2nd experiment: } 3 \text { EUR } \\
\text { Amount given 3rd experiment: } 2 \text { EUR } \\
\text { Amount given 4th experiment: } 1 \text { EUR }\end{array}$ & & & & \\
\hline $\begin{array}{l}\text { Amount given 1st experiment: } 0 \text { EUR } \\
\text { Amount given 2nd experiment: } 0 \text { EUR } \\
\text { Amount given 3rd experiment: } 0 \text { EUR } \\
\text { Amount given 4th experiment: } 0 \text { EUR }\end{array}$ & & & & \\
\hline
\end{tabular}

Please make ONE mark in each ROW! 